\title{
Turn organization and bodily-vocal demonstrations
}

\author{
Leelo Keevallik
}

\section{Linköping University Post Print}

\section{Tweet}

N.B.: When citing this work, cite the original article.

Original Publication:

Leelo Keevallik, Turn organization and bodily-vocal demonstrations, 2014, Journal of Pragmatics, (65), 103-120.

http://dx.doi.org/10.1016/j.pragma.2014.01.008

Copyright: Elsevier

http://www.elsevier.com/

Postprint available at: Linköping University Electronic Press

http://urn.kb.se/resolve?urn=urn:nbn:se:liu:diva-109201 


\title{
Turn organization and bodily-vocal demonstrations
}

\begin{abstract}
The study focuses on turns in interaction that involve a bodily-vocal demonstration: an embodied demonstration that is accompanied by a non-lexical vocalization. It shows how the temporal organization of these demonstrations contributes to participant treatment of them as a part of a turn-constructional unit, mostly as its completion. It is also suggested that a bodilyvocal demonstration may function as a separate turn-constructional unit, with a transition relevance point before it, and other participants refraining from action before its completion. Vocalizations, occasionally with coherent pitch contours of intonation units, are argued to render bodily displays vocal space within turns-at-talk. After a bodily-vocal demonstration, the turn-constructional unit can be recompleted with verbal devices, displaying further similarity to verbal-only turns. The analysis calls into attention the relevance of embodied behavior to the emergence of units in conversation.
\end{abstract}

\section{Turn organization and bodily-vocal demonstrations ${ }^{1}$}

\section{Introduction}

The recent explosion of studies on temporally evolving interaction in an embodied world has substantially transformed the way we think about language and its role in human sensemaking. On the one hand, it has become clear that the building-block understanding of grammar should be abandoned in favor of a dynamic resources-and-processes approach (Ford, 2004; Linell, 2013). On the other, we have learned that speaker turns are supported by embodied devices, such as gaze and gesture (Goodwin, 1980; Stivers and Sidnell, 2005; Mondada, 2006, 2007; Enfield, 2009). Besides, turns have themselves been shown to contain complex spates of multimodal interaction (Iwasaki, 2011), to the extent that they should more adequately be conceptualized as "a temporally unfolding, interactively sustained domain of multimodal conduct through which both the speaker and recipients build in concert with one another relevant actions that contribute to the further progression of the activity in progress" (Hayashi, 2005: 21). The current paper ventures further into the dynamic methods of doing language, focusing on turns where bodily conduct interplays with grammar in the initiation, projection and completion of the emerging unit.

Bodily-visual displays have been shown to figure in several ways in turn- and unitconstruction. Gestures can assist in turn-taking (Mondada, 2007) and contribute crucially to sense-making (Enfield, 2009); bodily-visual displays may be produced at turn-completion and add a stance to it (Ford, Thompson, and Drake 2012). These studies show that in addition to syntactic, prosodic and pragmatic matters (Ford, Fox, and Thompson, 1996; Ford and Thompson, 1996), embodied behavior can be relevant in turn organization. This study focuses on cases when embodied demonstrations are accompanied by non-lexical vocalizations. Vocalizations constitute a method of filling up the vocal space during the bodily-visual contribution. Earlier studies involving vocalizations in interaction have demonstrated a number of interesting phenomena. Together with gestures and other semiotic resources,

\footnotetext{
${ }^{1}$ The study has been financed by Riksbankens Jubileumsfond project "The bodily component of grammar".
} 
nonsense syllables can help to build entire turns and actions (Goodwin, Goodwin, Olsher 2002). Vocalizations have been shown to occur in enactments (such as response cries) and "body quotes" in interaction (Streeck, 2002; Sidnell, 2006; Fox and Robles 2010). They can also accomplish the crucial actions of assessing and directing in music and dance instruction (Keevallik 2013; Tolins 2013). The term bodily-vocal demonstration used for the phenomenon in the current study underlines the primacy of the embodied display, suggesting a gentle boundary between bodily-vocal demonstrations and emotional vocal displays, including response cries, as discussed in e.g. Fox and Robles (2010), as well as a slight difference from vocal performances that primarily represent sounds, such as car horns and music (Sidnell 2006: 383; Tolins 2013). In bodily-vocal demonstrations the vocalizations support the bodily displays, reinforcing their interactional task. It is argued that these demonstrations are turn-organized and by extension, other kinds of bodily displays may be too, even when they are accompanied by silence. Pauses in the stream of talk may in fact be filled with segments of embodied action that build interactional units, as is nicely shown by Seo and Koshik (2010) or bring them to a recognizable completion, as argued in Keevallik (2013).

Turn-organization has canonically been understood in terms of grammar and the combinatory possibilities of various turn-constructional units (TCUs) (e.g. Schegloff 1996). In the programmatic article by Sacks, Schegloff, and Jefferson (1974), TCUs were outlined as sentential, clausal, phrasal, and lexical constructions. This followed from the authors' distinct interest in conversation and from working with telephone data. Later research has underlined the dynamic nature of turns as opportunities for different actors to participate in (Goodwin and Goodwin, 1987; Hayashi, 2005; Iwasaki, 2011), and suggested that units can be built by combining clausal syntax and bodilu demonstrations (Keevallik, 2013). Interactional linguists have started to talk about on-line units that are sensitive to local contingencies and constantly available for renegotiation (Ford, 2004; Auer, 2005; Linell, 2013). This research has taken into consideration different modalities involved in the process of unit-construction, in particular gestures and gaze. The present study aims to propose that similarly to grammatical elements, the embodied demonstrations may be in the service of providing the participants with recognizable initiations and projections of possible completion points, thereby being part of the systematics of turn-taking. This is what the seminal paper claimed:

We have proposed that the allocation of turn-space is organized around the construction of the talk IN the turns. That organization appears to key on one main feature of the construction of the talk in a turn - namely, that whatever the units employed for the construction, and whatever the theoretical language used to describe them, they still have points of possible turn completion, points which are projectable before their occurrence (Sacks, Schegloff, Jefferson, 1974: 720).

In addition to "construction of the talk" we would suggest including "embodied resources" among the means used for designing turns and TCUs. This is controversial, as turns have traditionally been understood as turns-at-talk, as vocal conduct. But occasionally turns seem to be developed with other types of materials, so that their allocation is also organized around these alternative materials. Talk clearly benefits from the specifics of grammatical projection. It also imposes physical demands on vocal space. On the one hand, turns built with linguistic resources interchangeably with bodily ones may be initiated and completed similarly to verbal-only turns. On the other hand they also display some differences. First, embodied displays may be accomplished or held during talk. And in contrast to this, the vocal turnspace can be filled by a non-lexical vocalization while the body performs. Second, embodied 
displays do not necessarily have an elaborate internal (e.g. grammatical) structure that corresponds to verbal units. While linguistic projection is based on knowledge of how the elements of a superordinated category are serialized in online speech production (Auer, 2009: 180), the body is not usually organized around superordinated categories. Characteristically, initiation and completion of such units is better understood with close attention to the ongoing activity, which may feature intrinsic starting and stopping points, or home positions $(\mathrm{Li}$, 2013). In the following, bodily-vocal demonstrations will be analyzed in regard to their potential of constructing separate TCUs.

Two types of video data are used in the current study. First, a workplace meeting between an artist, a head of a theater workshop and several craftsmen, comprising 1.5 hours of data in Estonian. Second, there are approximately 30 hours of dance classes in English, Swedish and Estonian. All the participants have agreed to the recording and publication of the materials.

The paper starts by scrutinizing a case where a bodily-vocal demonstration potentially constitutes a TCU during an ongoing professional argument. It will then move on to show how a bodily-vocal demonstration can complete a TCU and how participants negotiate its completion in an activity-specific manner. It is also discussed how units involving bodilyvocal demonstrations can be built further. Finally, it is argued that close analytic attention to the body may reveal that participants occasionally orient to qualitatively different completions as compared to grammatical-lexical ones.

\section{Bodily-vocal demonstration as a TCU?}

TCUs have been characterized as contingently emerging spates of language, defined by the relevance of turn-transition at the end, as oriented to by the participants (Sacks, Schegloff, Jefferson 1974; Ford and Thompson 1996; Selting 2000). They may be of variable length and grammatical substance, and furthermore expandable after completion points. One of the basic characteristics of TCUs is that once initiated, a possible completion is projected in a way that enables other participants to match their subsequent action with the potential completion. Projections may be very short, such as the duration of a single particle, but they may also be complex with several projective layers activated simultaneously (as illustrated in Auer, 2009). However, it is yet to be argued that an embodied demonstration accompanied by a vocalization such as drrrrrr can constitute a unit of its own. In the current section we will look at a case that suggests exactly that.

Excerpt (1) comes from a meeting between an artist, a head of a theater workshop, and an assistant. The artist has designed a set for an opera performance, which is currently under construction at the workshop. The head is responsible for building and transporting the set within the budget, while the role of the assistant designer is to oversee the everyday progress of the work and to translate the artist's ideas into actual materials. It is a context where embodied demonstrations are frequently used to discuss yet-to-be-built structures as well as ideas that may materialize into inhabitable spaces in the future. A similar creative environment of an architectural bureau has been analyzed by Murphy (2005), who has demonstrated the central role of gesture in conjuring up an imagined world. Embodied demonstrations in these contexts are a major device of visualizing the future space as well as achieving intersubjectivity at the current moment.

The meeting takes place at the time when some structures have already been built for the 
opera scene and it has turned out that the artist's original idea of twirling fabric circles has been misread in her drawings. Instead, the workshop has prepared stiff structures. The head calls them "roofs" in the excerpt. The workshop blueprint is shown in Figure (1). It represents circular structures that seem to be stiff, instead of formed by movement, which was the artist's original idea.

Fig.1. The workshop blueprint of the "roofs".

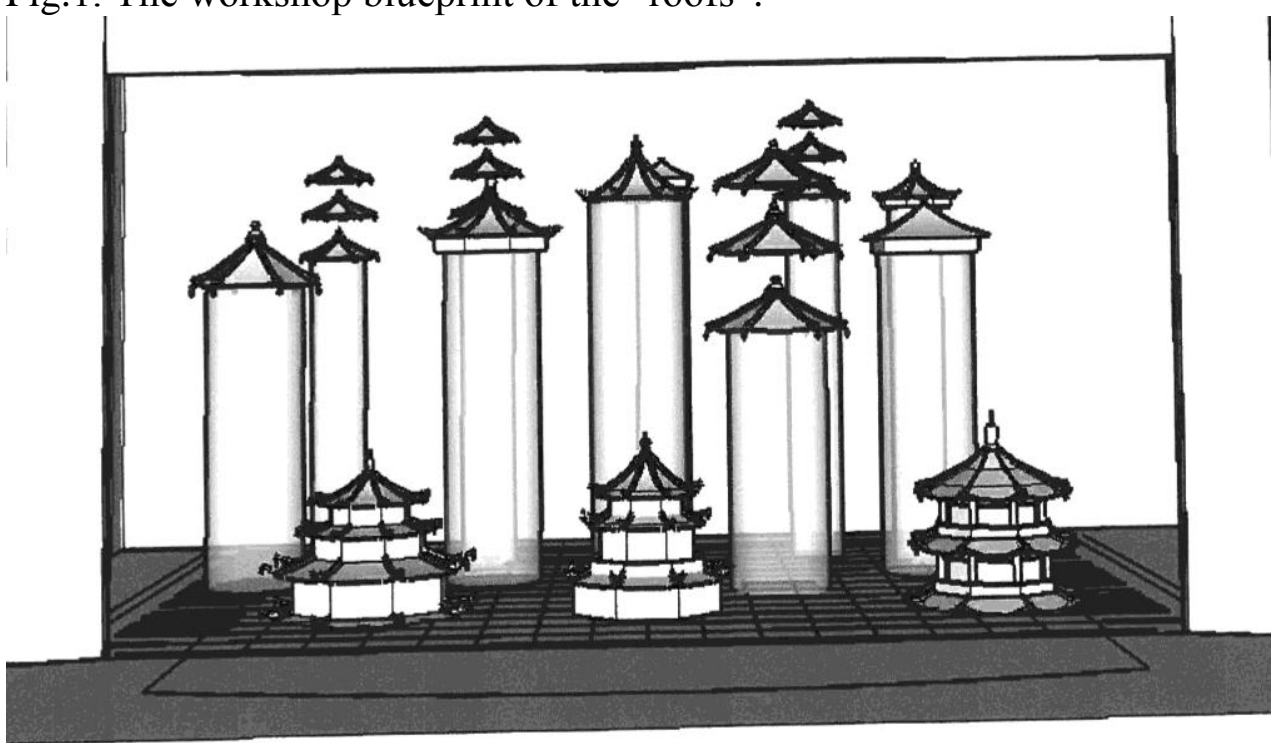

At the beginning of the excerpt, the artist explains her idea of twirling fabric by invoking the Chinese circus (lines 1-4) and receives answers that display understanding by both the assistant and the head of the workshop. The latter, in fact, suggests the image of "plates" (line 5). He then, however, goes on to offer an alternative solution to rotate the "roofs" instead, insisting that the visual effect would be the same ${ }^{2}$ (lines 14-17). The turn where the artist contests this claim will be our analytic focus (lines 20-21, 23-24).

(1) Set design meeting (Estonian): twirling circles

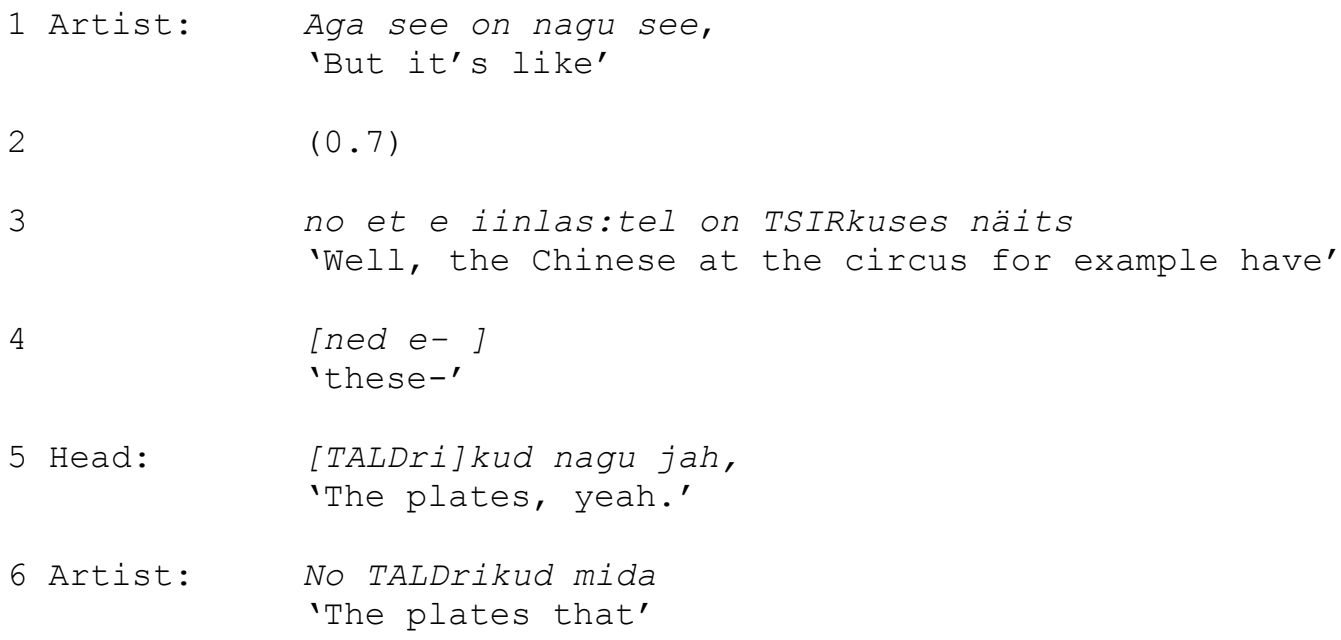

\footnotetext{
${ }^{2}$ It remains underspecified at this point, whether the roofs would look like rotating plates or twirling fabric.
} 
[nad va- JALgade peal keer- ta akkab lisalt et-]

'they rotate on their feet, it simply begins-'

8 Assist: [Lihsat et akkab- KANgas akkab keerlema lsalt,] 'It simply begins- the fabric begins to twirl.'

9 Artist: et noh, [see on- ]

'so that, it's-'

10 Assist:

[ainult jah, ]

'simply, right,'

11 Artist: See on tsentripeTAAl ju tegelt vist.

'It's actually centripetal probably'

12

või -fuGAAl ei, (0.2) no vahet pole.

'or -fugal, well (0.2) never mind.'

13

[ (suva) no ÜHEsõnaga.

'(whatever) Anyway.'

14 Head: [Nüüd me paneme lisalt need KA] tused

'Now we simply make the roofs'

15

pöör [ lema.]

'rotate.'

16 Artist:

[ Len]dav TAL]drik tegelt. SIsuliselt.

'Flying saucepan actually. In principle.'

17 Head: See on SAma efEKT ju.

'It's the same effect.'

$18 \quad(0.5)$

19 Assist: Ta:- [ (ma saan -) ]

'It- (I can - )'

20 Artist: $\rightarrow$ [A see on just] SEE lahe et, but it be:3SG precisely it cool that

'But the thing that is cool is that'

21

-> ta $k$ - nagu Tekib vata. (.)

it like appear:3SG PAR

'it like appears, $y^{\prime}$ see' $^{\prime}$

22 Head: $\quad{ }^{\circ}[\mathrm{a}],{ }^{\circ}$

'uh'

23 Artist: $\rightarrow$ [d]rrTrrer,

$24 \quad \rightarrow$ ja sis tõmbub TAgasi nii.

and then retract:3SG like.this

'and then retracts like this.'

$(4.4)$

26 Assist: Noo kui sul see PÖÖrl-PÖÖrlemismehhanism 'Well, if you have the rotation mechanism' 


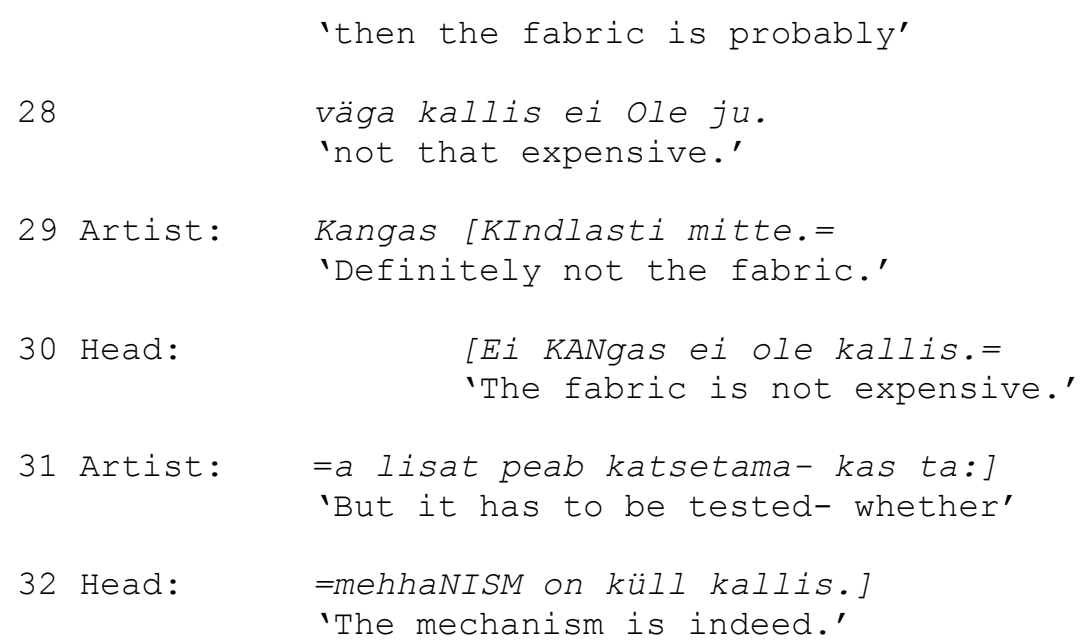

The turn in lines 20-21 is produced as part of an argument. Disaligning with the head's proposal, the artist initiates her turn with $a$ 'but' and instead of accepting the head's offer or agreeing with his assessment that rotating roofs would look the same, she provides a positive assessment of her own original idea. The first transition relevance place (TRP) is after vata, approx. ' $y$ 'know, you see'. At that point, the relevant information about why the rotating roofs would not be as cool as the twirling fabric has been verbally expressed (ta nagu tekib 'it like appears') as well as illustrated by the simultaneous bodily action. On just, approx. 'precisely', the artist lifts her hands (as shown in Figure 2) and on the first syllable of vata she does small quick circular movements with a single finger (in a position shown in Figure 4). There is a clear pitch fall at the end of tekib 'appears', and the pitch stays low on vata. Vata is usable both as a turn-initial and a turn-final particle (Keevallik, 2003: 205-207) and its turnstatus can therefore be ambiguous here. However, the short pause after vata suggests that it is a part of the prior unit. On vata the artist is gazing at the head, the target of her counterargument, but the head has turned his gaze away already on tekib 'appears' (as can be seen in Figure 4). He is now gazing at the computer screen where the blueprint is displayed (the blueprint is shown in Figure 1). Immediately after vata, the head responds with a minimal $a$, showing his analysis of the turn-so-far as having been complete.

The artist, however, chooses to continue with an embodied demonstration accompanied by the vocalization drrrrr. The vocalization is done as a separate prosodic contour that iconically goes up in the beginning and falls slightly in the end (Figure 3). It follows the speaker's hands that move upward, opening up, and then turn downward. The hands represent the fabric that moves from hanging position to plate-like structures when twirled, and back to hanging. This is a "modeling gesture" (Enfield, 2009: 113-148). Framegrabs with the gesture and the gaze directions during the target stretch of talk are shown below (Figures 2,4-5). At the beginning of line 20 the artist has the gaze of the head who is seeking her response to his proposal and assessment. By line 23 he has turned away. Even though the assistant gazes at the artist during line 21 and at the beginning of line 23, she has also turned away by the end of line 23 (compare Figures 4 and 5). Both recipients have thereby disengaged visually.

(2) Focus turn in excerpt (1)

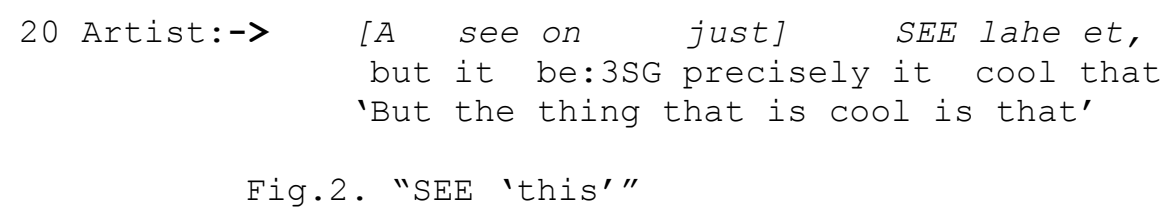




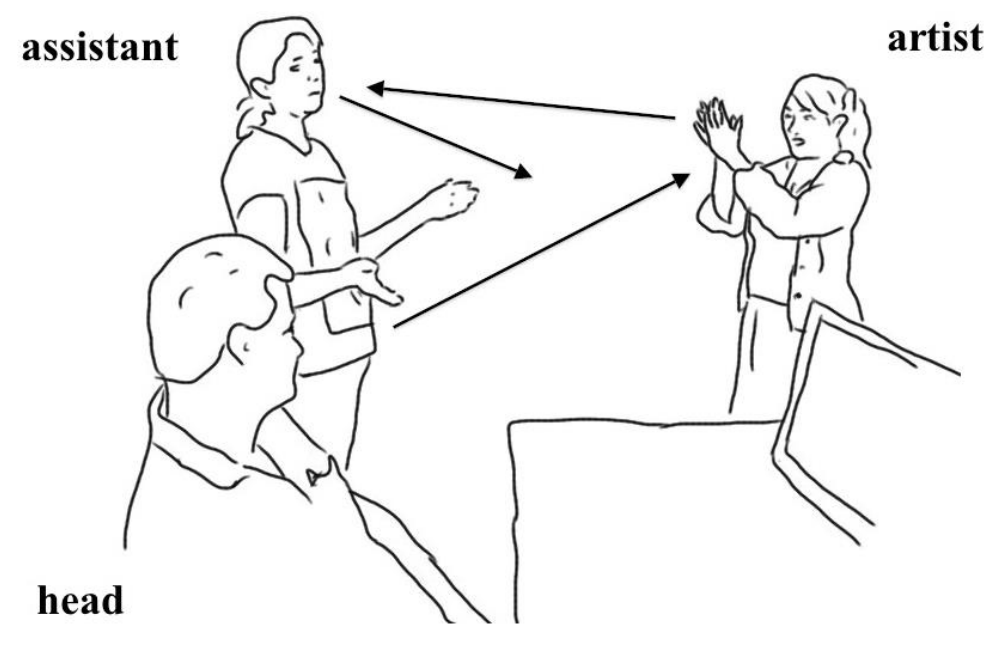

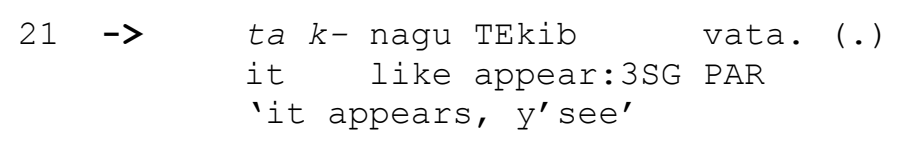

22 Head: $\quad{ }^{\circ}[a],^{\circ}$

23 Artist: [d]rrTrrre,

Fig.3. Pitch contour on "drrerrr"

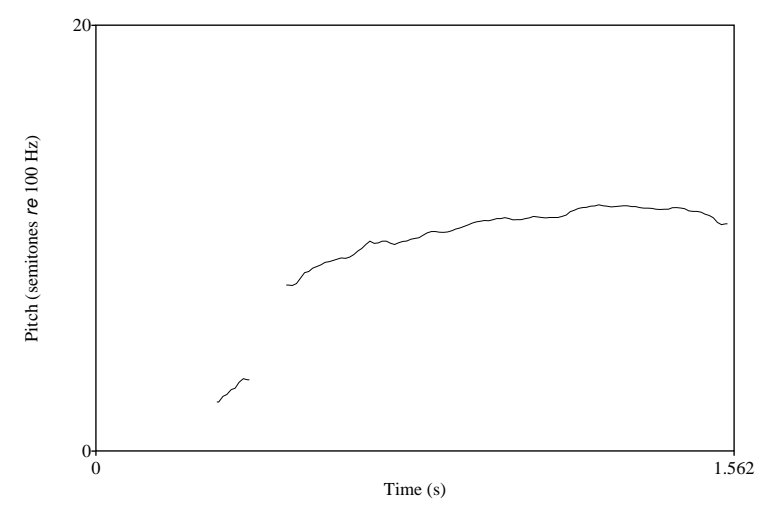

Fig. 4. "dr"

Fig. 5. "-rrr-"

\footnotetext{
${ }^{3}$ There may be a slight reflection of the head's $a$ at the beginning of the pitch curve but his voice is very low in relation to the artist's voice.
} 

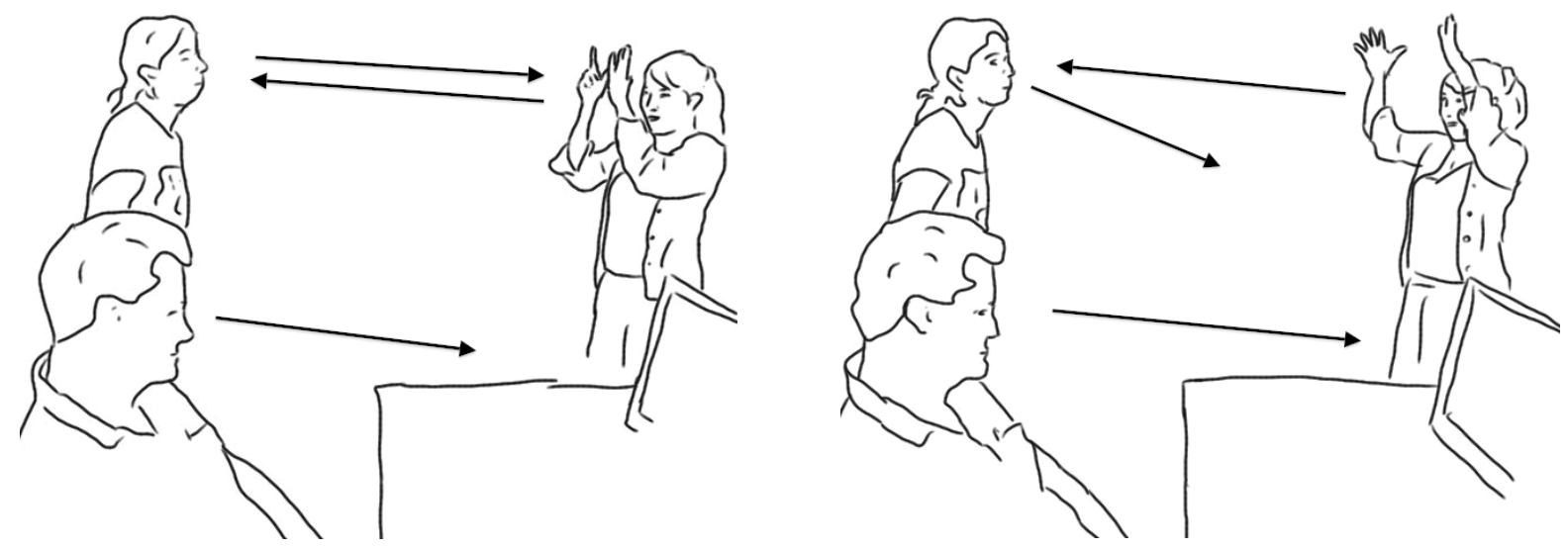

The issue here, for participants as well as analysts, is what kind of an element is this bodilyvocal demonstration? It is done after a syntactic, prosodic, and pragmatic completion of the prior unit and is thus not projected in prior talk. In this regard it is similar to an increment, "a grammatical extension of the already completed unit" (Ono and Couper-Kuhlen 2007: 505).

Research on increments has featured discussions on the status of these extensions that may be syntactically, semantically, and prosodically dependent on, or independent of, the prior unit (see particularly Couper-Kuhlen and Ono 2007a). Furthermore, the question whether the action import of an increment can be independent has been targeted (with Schegloff (1996: 90-92) and Fox, Ford and Thompson (2002: 26-30) representing different takes). For the current case, the main challenge in this regard is to establish the syntactic-semantic role and the grammatical function of the bodily-vocal demonstration, in the case of it having any. It indeed builds on the prior unit and illustrates what is meant by 'appearing'. Semantically it corresponds to a manner adverb. A manner adverb, however, would have been a syntactically matched continuation, a prototypical increment called a glue on (Couper-Kuhlen and Ono 2007b: 515-516). Even though this kind of paradigmatic reasoning is common in syntactic analysis, it seems to be an unnecessary simplification to force the bodily-vocal demonstrations to fit a specific word class or a syntactic category. It is a qualitatively different kind of element that can nevertheless be fitted with language and syntax. In the current case, the drrrrrr together with the bodily demonstration therefore seems to qualify as a turnextension, rather than a TCU-extension. It is a separate TCU that semantically expands on the content of the prior, making the 'appearing' of the fabric circles visible for the recipients. Its left boundary was attended to by the head, when he produced a token of recipiency at its launching, and its progress was unhindered by the recipients who withheld any action. These are both signs of participant orientation to the ongoing unit.

The next practical and analytic problem concerns the treatment of the demonstration as complete. At the highest point of the artist's hands during the latter half of drrrrrr, nobody is looking at her (as shown in Figure 5). This may be the reason why she continues by giving a clausal comment on the current downward movement of her hands and pitch ja sis tômbub tagasi nii 'and then retracts like this'. The ja' and'-preface marks this as a next unit-at-talk. In other words, there was a TRP at the point when her gesture had illustrated the 'appearing' of the shape, even though the recipients chose not to respond. One action was complete, one syntagmatic unit was terminated, as can be judged by the fact that the next one is swiftly initiated with a conjunction ja 'and'. However, the prosody is ambiguous at this point and the hands have yet to return to their home position (Sacks and Schegloff, 2002). Prosodically, the drrrrr-unit is extended by the subsequent clause that starts on the falling pitch latched to it (as shown in Figure 6). The clause provides a verbal description of what happens with the 
fabric when it comes down again. The depictive gesture is brought back to home position by the end of the clause.

(3) Focus turn in excerpt (1), continuation
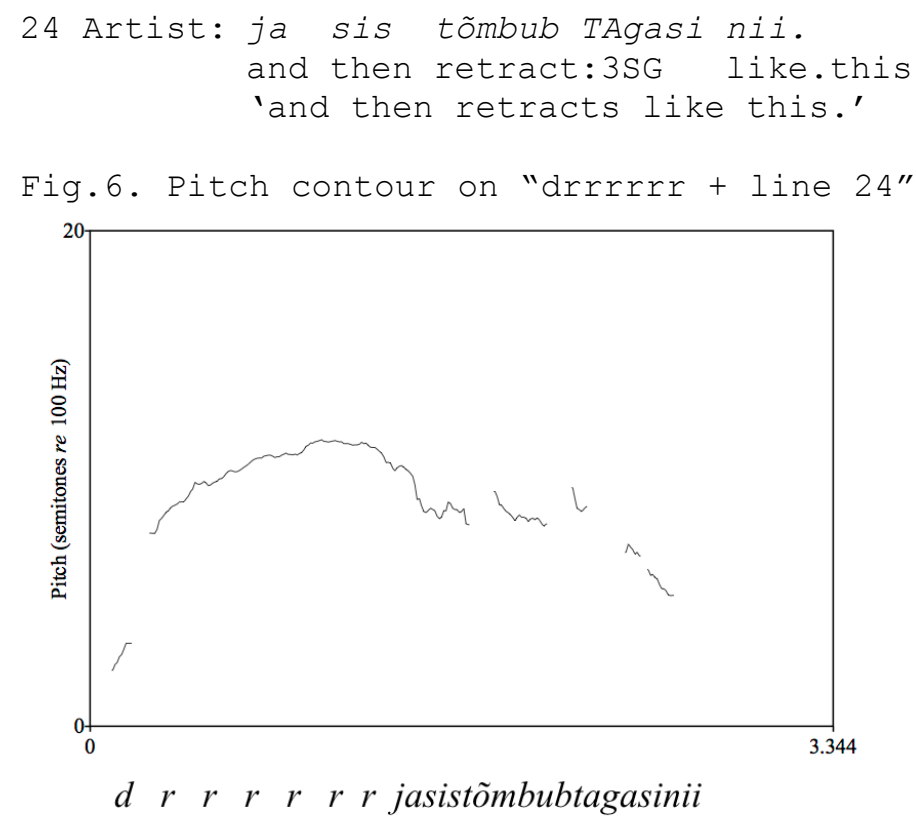

Fig.7. "TAgasi 'back'"

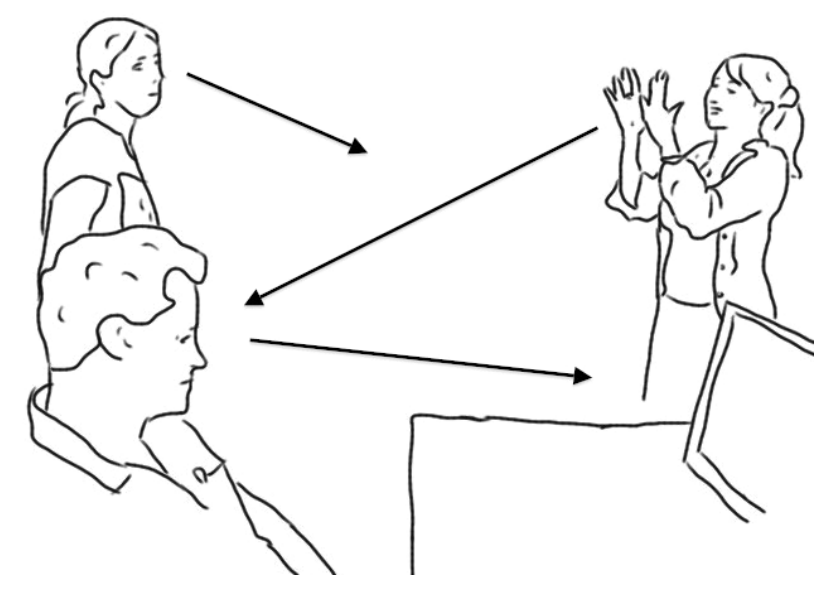




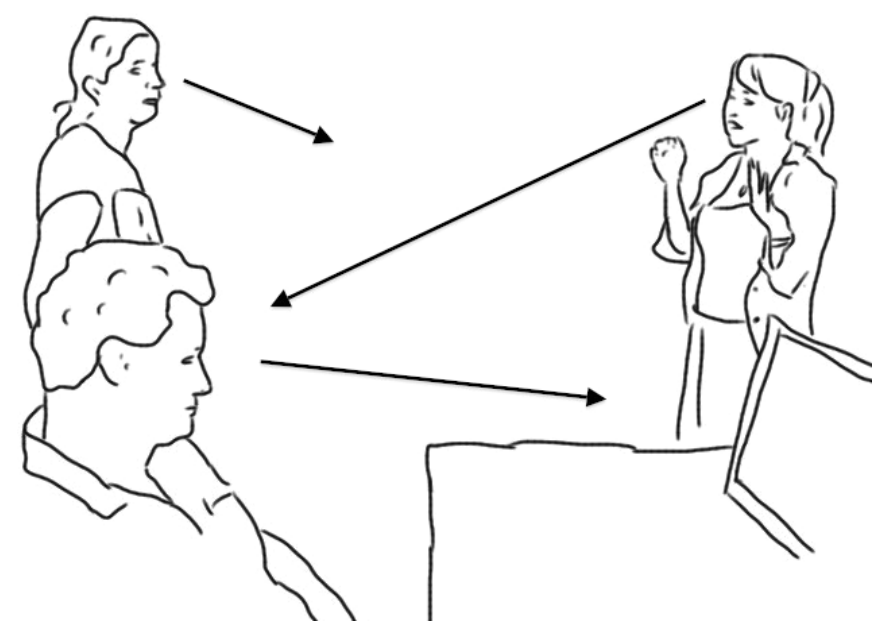

The artist has thus accomplished a multi-unit turn in lines 21 and 23-24, continuing to talk and act across two TRPs, one before and one after the drrrrrr. The bodily-vocal demonstration can therefore be understood as a separate TCU with its own initiation and completion. It amounts to an iconic description of the twirling cloth with the non-lexical vocalization depicting the gradual emergence of the structure. The increasing-decreasing height and loudness of the vocalization represent the speed of twirling and possibly the size of the structure, thus nothing that has to do with sound (especially since an opera performance cannot be disturbed by any noise from the set). This pitch curve also nicely corresponds to pitch use in intonation units (rise-fall). Crucially, the bodily-vocal demonstration is here not deployed as a replacement for a lexical item, as can be the case when embodied displays are used in L2 conversations (Gullberg, 1998; Olsher, 2004; Mori and Hayashi, 2006). It is designed as an alternative and additional way of sense-making and elaboration. It aids collective imaging of movement, as has been described in a study of an architectural firm by Murphy (2005). Movement is especially difficult to describe in the form of the two- or even three-dimensional blueprints used by architects as well as stage designers, and in the current case this is exactly what has caused a misunderstanding at the workshop. In short, the drrrrr + gesture display a distinct semantic-referential content designating the event of moving and a separate pitch curve, both of which could be supportive arguments for treating it as a separate unit.

The fact that there is no actual turn-transfer at the TRPs before and after $d r r r r$ is related to the overall activity context of arguing. The bodily resources are here in the service of a negotiation in a complex relationship between the professionals who have diverging agendas and responsibilities. By refraining from taking the turn, the head of the workshop and the assistant display resistance to, or careful consideration of, the artist's objection. Even after the complex turn is completed in line 24 , the recipients refrain from taking the next turn. During the long pause in line 25 the artist keeps her hands held up in the air, as shown in Figure (8), further lengthening the opportunities for the timed initiation of next action. The assistant finally terminates the pause and partly takes sides with the artist (lines 26-28).

To summarize, the first case suggested that a bodily-vocal demonstration may constitute a separate TCU in a multi-unit turn. Bodily and verbal segments can interchange within the course of a turn, in addition to overlapping - the latter having been demonstrated in numerous earlier studies on gesture and enactments. It has been clear that bodily displays, including reenactments in storytelling (Sidnell, 2006) and body quoting (Streeck, 2002), are turn- 
så det blir jätteHÄFtiga baksteg,

'So there are super strong backsteps'

5
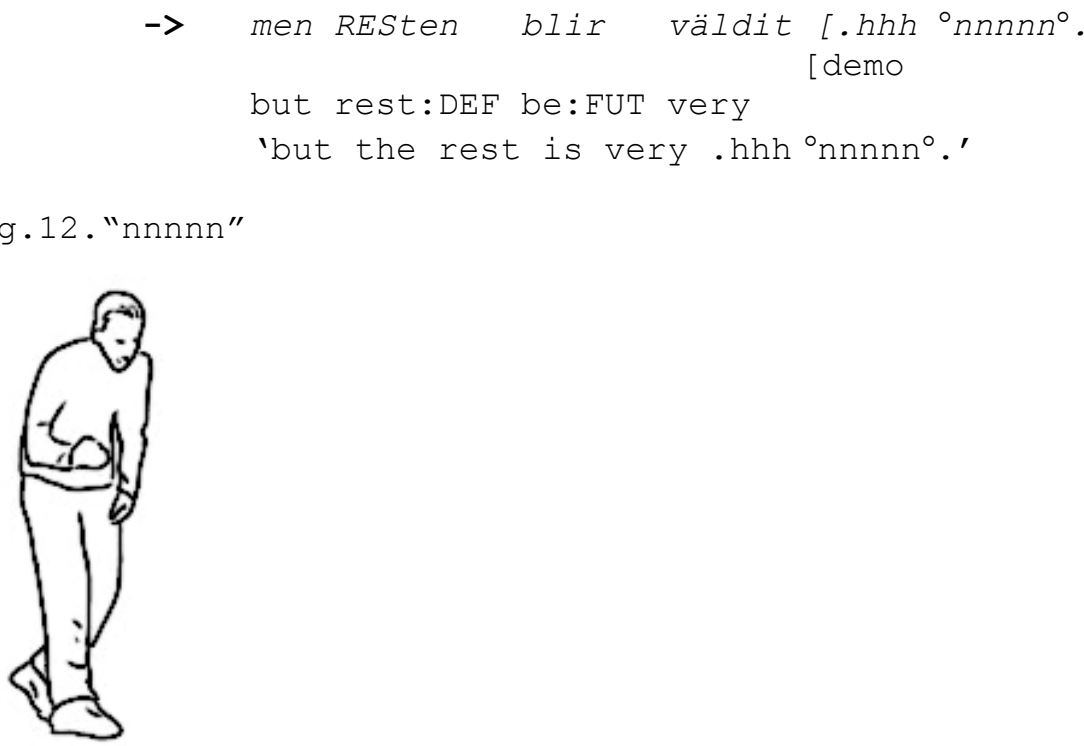

The bodily-vocal demonstrations bring the three units to a completion. In line 2, the quotative $b a$ (Eriksson 1995) syntactically projects a continuation and the projection is realized in a bodily-vocal format. $\mathrm{Ni} \mathrm{ba}$ 'you're like' is immediately followed by a powerful step (the beginning of which is illustrated in Figure 9) and the accompanying vocalization $P U: \therefore$ with a terminal intonation at the end ${ }^{4}$. The unit thereby comes to a completion. The next unit is initiated during the ongoing performance with yet another projective quotative form, $\stackrel{a}{s}$ sa $b a$ 'and then like'. The performance continues after the syntax has been discontinued, but this time the inadequately small steps (Figure 10) are accompanied by a different vocalization mqmqmq mmqmq., produced with very low volume and level pitch. The teacher almost keeps her mouth closed and mumbles. This is in sharp contrast with the high volume, high start in the pitch range and a clear fall in pitch on $P U: \because$. The contrast illustrates iconically the difference between "heavy" and insufficiently "heavy" parts of the step combination. The completion of the second unit is achieved at the end of mmqmq, because this is where the intonation falls and the demonstration of the incorrect performance comes to an end. A new correct step is done after it with full power (Figure 11), again accompanied by a high pitch and volume PU:M.

Finally, the syntactic initiation in line 5 men resten blir väldit 'but the rest is very' projects yet another continuation that is realized in the bodily-vocal demonstration. This time, the teacher is not dancing but standing still, and enacts a humble posture with a clumsy hand movement, representing the timid dancing style (Figure 12). The vocalization nnnnn that starts a short

\footnotetext{
4 "Body quotes" in English and German, albeit involving response cries, have been studied in Golato (2000), and Streeck (2002).
} 
while into the bodily demonstration, is produced very high in the speaker's pitch range and at a markedly low volume, again underlining its contrast with the correct heavy way of stepping. None of the syllables in vocalizations of the current excerpt have conventional meanings: they are not represented in the comprehensive dictionary of Swedish (SAOL) and are more or less ad hoc inventions. Instead of representing sounds or emotional states, they are in the service of the pedagogical activity of dance instruction. While stops are used to mark the properly heavy steps, liquids $m$ and $n$ dominate in the accompaniment of the incorrectly light performance. Pitch height, volume and sound quality all appear useful when making a pedagogical point about bodily behavior. The bodily performances are equally contrastive, with correct moves performed nicely and the incorrect versions regularly done as caricatures (on quoting the bodies as caricatures in these data, see Keevallik, 2010).

In short, the above example showed how bodily-vocal demonstrations emerge as part of TCUs in dance teaching. The resulting constructions involve a syntactic initiation and an embodied completion: they are syntactic-bodily units (Keevallik, 2013). On the one hand, vocalizations are deployed to keep the turn space that may otherwise be subject to transition, but on the other, there are activity-specific reasons for using the vocal tract simultaneously with the bodily demonstration. In alternative activities, sounding and singing may be relevant, as in examples $(5,6)$.

(5) Orchestra rehearsal (Weeks, 1996: 269)

And again you still lose contact and play beebee do da ((sings))

(6) Clarinet instruction (Tolins, 2013: 53)

$$
\text { But it sounds a little bit urrrllliiaa (vocalization)) }
$$

In addition, there are numerous cases reported in the literature in which syntactic projections can be realized with merely the body. A list of them is presented below.

(7) Teacher at a language class (Lerner, 1995: 120)

Doorknob is (0.6) ((teacher pantomines the use of a doorknob))

(8) L2 speakers (Olsher, 2004: 232-233)

Paste is ((pantomimes scooping paste from jar))

(9) Physical therapy patient, in Swedish (Martin, 2004: 126)

$\AA$ sà sku jag 'And then I should' ( (takes a breath and sighs, pulls shoulder down))

(10) A L1 speaker talking to L2 speakers, in Japanese (Mori and Hayashi, 2006: 201)

nanode:: (1.0) hurui:: (.) kuruma wa:: (0.2) nedan ga::

'So::, (1.0) as for o::ld (.) ca: :rs, (0.2) their pri::ces'

((moves open right hand downwards repetitively))

(11) String quartet master class (Haviland, 2007: 165, 167)

so you have- you know less possibility to be: ( (plays badly at

the tip))

So that you can um- ((plays))

(12) Dance teacher in a class (Keevallik, 2013: 7)

Sis tuleb 'Then comes' ((demonstrates a dance move))

These examples show that participants treat some embodied demonstrations as turnorganized, whether a vocalization is involved or not. The current section has argued that 
bodily-vocal demonstrations, similarly to other embodied demonstrations, can realize a projection of a syntactically incomplete initiation. They constitute a regular technique of building TCUs at least in the three languages studied here. Bodily-vocal demonstrations can occupy turn-space. The vocalizations are easily adaptable to extended movement and thus extended turn-space, as they can be lengthened or repeated (see excerpt (4) above). There is likely to be a continuum of embodied phenomena from those occurring simultaneously with verbal turns, to those assisting in taking and completing turns, to the ones that occupy a fully authorized temporal slot on their own with a TRP at the end.

However, bodily-vocal elements as TCUs and TCU completions display some specific qualities as compared to verbal elements of talk, in particular when it comes to internal structure. They seem to be organized, initiated and completed in terms of the ongoing activity rather than in terms of grammatical well-formedness (which in itself may be a petrified form of action-specific behavior). In example (4) we saw how the extension and completion of the vocalizations $P U::$ and $m q m q m q$ mmqmq were determined by the length of the dance step combination, instead of any internal logic of the vocalization syllables. Below, we will look at how the length of a bodily-vocal demonstration, and thus a TCU, can be defined jointly by the participants.

\section{The extension of a bodily-vocal demonstration}

In order to accomplish a matching next action, participants' ability to project a completion of the current one is crucial. At the same time, we know that verbal units are expandable in time (Auer, 1992, 2009b; Couper-Kuhlen and Ono, 2007b, among others), which makes completion a contingent accomplishment. Even more so, recognizing completion in an embodied demonstration may constitute a practical challenge. Body movements are not necessarily segmentable (see, however, the phenomenon of home positions in gestures, Sacks and Schegloff, 2002; and body positions, Li, 2013), nor do they involve higher-order structures such as phrases or clauses in language. Nevertheless, participants regularly demonstrate their understanding of the completion of embodied segments as well as entire syntactic-bodily units. They withhold action when the still-projecting grammar is discontinued, and they initiate a next action when the multimodal contribution constitutes a comprehensible whole. The following excerpt (13) shows a case in point.

In this excerpt the teacher couple at a dance class has just finished a demonstration of a step variation and in line 1 the lead teacher summarizes its gist. Within the general organization of the dance classes in this study, it is clear that a transition to student practice is now imminent. The demonstration has been terminated, the teacher couple has just been dismantled and after uttering okay at the end of line 1 the lead teacher takes a leap toward the music equipment, which is also a sign that a practice will soon be underway. In line 5 the follow teacher initiates a unit that suggests a place in the step routine where the students should start practicing, a socalled structuring instruction (Broth and Keevallik, in press). She utters a preposition and an article (fro:: $m$ the::), thereby displaying that she has initiated a turn and a turn-constructional unit, recognizably a noun phrase. However, it ends up as a different kind of unit, a bodilyvocal demonstration. The teacher starts dancing immediately after the article and from now on the practical problem for the participants is where it can come to a completion. Importantly, the suggestion of a place to start is here addressed to the lead teacher, seeking agreement from him. The follow teacher, while vocalizing and dancing, is steadily gazing at the lead, as shown in Figure (13). 
(13) Dance class (English): from the

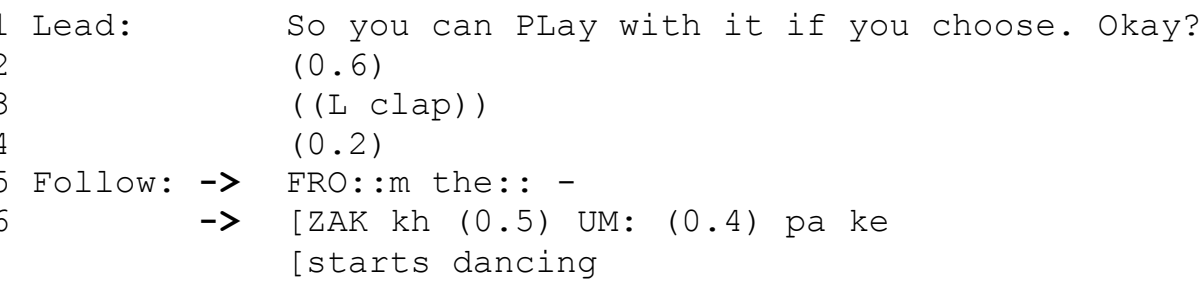

Lead (standing)

Follow (dancing)

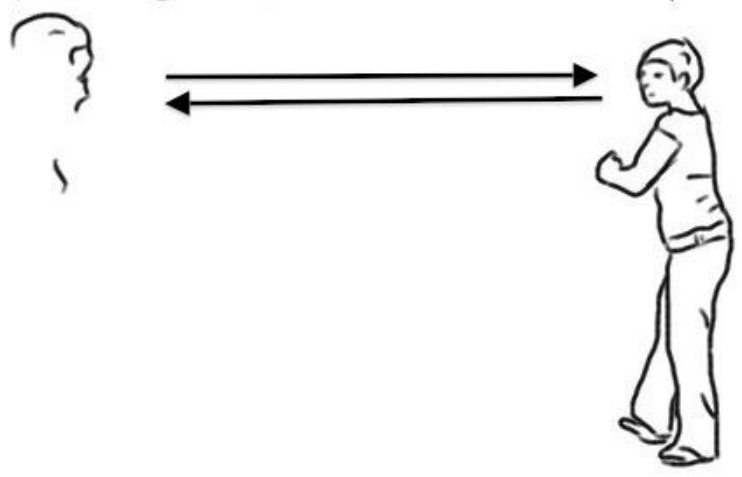

7

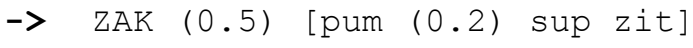

An embodied performance can be the optimal way of identifying a moment in the dance routine, which is why a syntactic-bodily turn emerges in lines (5-9). The follow's dance in this excerpt covers almost three eight-beat sequences within the dance routine, which takes a considerable amount of interactional time. The students are observing this because the performance will provide them with a crucial clue as to the beginning of the practice. Only after the agreeing response yeah by the co-teacher (in line 9) the follow teacher stops dancing and thereby brings the syntactic-bodily unit to a completion. The two teachers collaboratively define the completion and simultaneously accomplish an adjacency pair of a suggestion and an agreement. The suggestion emerged as consisting of two parts: a discontinued syntactic pattern and an embodied performance accompanied by vocalizations. The syllables used in the vocalization were all non-lexical, as in the above examples, and their primary function here was to accentuate the rhythm in the dance. At the same time, they contributed to extending the follow teacher's turn space also vocally.

The question is whether there is anything systematic about completing embodied demonstrations in parallel to grammatical completion. For one thing, similarly to what 
happens in conversation, the action has to be interpretable in order for a transition to a next turn to be possible. In excerpt (13), the performance may have continued so long because its beginning was generic, repeated at several points in the dance routine. The first distinctive step that allowed the lead teacher to identify the specific moment occurred at the end of line 7 , after which he indeed produced the agreement token. Thus, in the activity context of a dance class, it may be the logic and character of the dance that enable marking boundaries in the emerging units. In verbal as well as bodily practices, a turn has to amount to a complete action, which may warrant a multi-unit structure. Emerging units in an embodied activity may be qualitatively very different, such as in the current case where the dance is conventionally segmented into eight-beat structures. Even though the follow teacher in the above excerpt performed several "eights" in the dance, her initiation + performance arguably resulted in a single action and a single syntactic-bodily unit. The alternative ways of parsing in the performed action should not be accountable in terms of unit completion insofar they do not help to construct a coherent recognizable action at the current moment and for the pedagogical activity of determining a start for practice. This is of course a practical concern for the participants at every single instance, and here we could see participant orientation to a single coherent action initiated by fro:: $m$ the:: and completed by a long bodily-vocal demonstration. The lead teacher's agreeing yeah brought it to a completion, as the follow stopped dancing soon after it.

The existence of the multimodal practices outlined above bear consequences with regard to the practical accomplishment of completion when segments of talk interchange with segments of bodily displays, in particular when talk is resumed after the bodily-vocal demonstration. This will be discussed in the following section.

\section{Resuming talk after a bodily-vocal demonstration}

Excerpt (1) above demonstrated a multi-unit turn with a bodily-vocal demonstration occurring after a completed verbal unit and before the initiation of a new verbal unit. Considering that TCUs can be completed with bodily-vocal demonstrations (as shown in sections 3-4), there are further complex ways how talk can interchange with bodily displays within a single turn. For example, an already complete syntactic-bodily unit can be recompleted with a verbal increment (Keevallik, 2013: 12-13). The increment can either be an add-on that grammatically extends the prior unit, or a replacement (Couper-Kuhlen and Ono, 2007b: 515), a verbal substitute of what was demonstrated by the body. Naturally, in both cases the participants may still orient to completion after the bodily display. Let us look at a case of an add-on after a bodily-vocal demonstration.

In excerpt (14) from a dance class, the teachers stand facing each other, demonstrating a "more parallel" constellation of their bodies (lines 1-2). In line 3, the follow teacher initiates a TCU so it's not this that is brought to a completion by a short bodily-vocal demonstration.

(14) Dance class (English): feeling

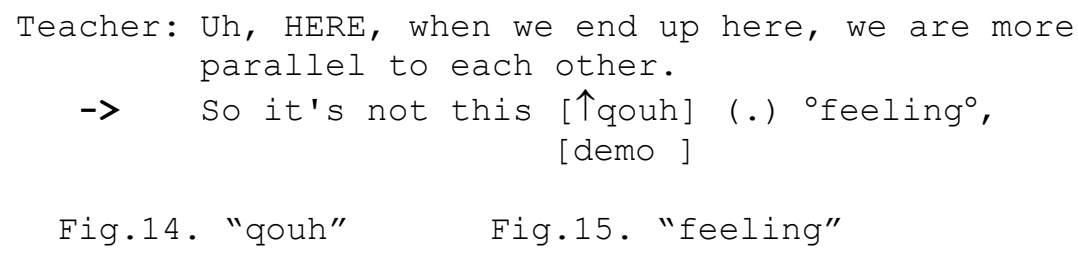



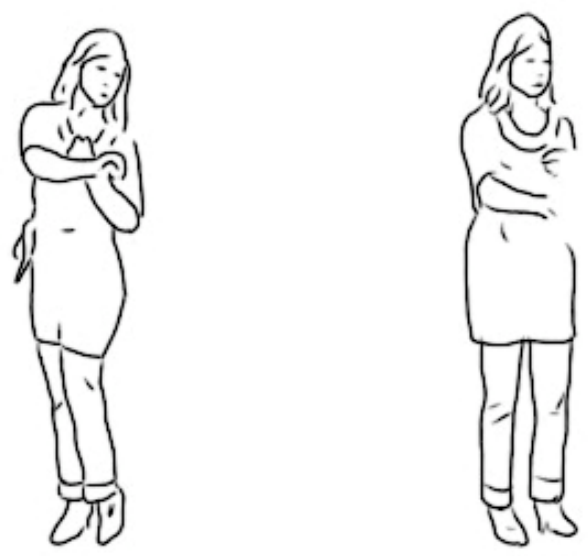

(0.4) it's more (0.2) [side to (.) side.]

During the syllable qouh the teacher demonstrates a body twist (as shown in Figure 14), the wrong one in this step. In order to achieve this demonstration on time, she initiates the movement already on not, letting go of her partner's hand. By the end of qouh she has almost turned back to her original position, which serves here as a home position for her body (as shown in Figure 15), suggesting a completion. The qouh is also produced with a rising prosody that could be heard as completing a unit, while feeling is said after a pause and very low, which matches the possible features of an increment. A syntactic-bodily unit represented by so it's not this qouh is a separate turn-constructional unit consisting of projective syntax, including a cataphoric demonstrative, and an embodied completion. The bodily-vocal demonstration in itself provides fully specified information about what the body should not be doing. The noun feeling is added incrementally, it is quite redundant and imprecise as compared to the demonstration. In any case, the completion of syntactic-bodily units may be renegotiated, similarly to other units in interaction.

The last example illustrates how embodied completions can be accomplished and renegotiated within the course of a turn, showing that there may be more completion points than the syntactic-lexical modality alone makes visible. Non-lexical vocalizations generally enable a variety of interactional interpretations, such as $u h$ and $u m$ are characteristically used for holding the turn in a word-search, but vocalizations are also flexible enough to coordinate the bodily demonstration with talk. The combination of body movement and vocalization can indeed bring a unit in talk to a recognizable completion. This is also why it is important to be analytically attentive to embodied demonstrations when studying turns: they can accomplish transition relevance places on their own. While body has been proved to be an important supportive means of turn-formatting (Hayashi, 2005; Stivers and Sidnell, 2005; Mondada, 2006, 2007), examples in the current study suggest that separate turn-slots may be occupied by the body, showing further alternatives to how participants project and accomplish unit completion. They orient simultaneously to multiple orders of temporality (Goodwin, 2002). Projection and completion, as central aspects of unit-construction, function across modalities.

\section{Conclusion}

The paper discussed ways of coordinating verbal and bodily behavior so that bodily demonstrations potentially emerge as TCUs or bring them to a completion. Vocalizations during the bodily demonstrations were shown to function as coordinating devices that fill the 
simultaneous vocal turn-space. The paper showed that turn segments involving incomplete and otherwise projective syntax can be understood as coherent and complete contributions if the subsequent bodily behavior is taken into account. This is obvious in cases where another participant initiates an appropriate next action after the bodily-vocal demonstration or when the current speaker goes on to initiate a new syntactic unit after it. If that does not happen, the analyzability of the embodied segment may be more problematic. As bodily displays are not structured in the way verbal units are, their boundaries are negotiable in different terms. For example, stopping the dance may effectively complete a unit that involved a dance demonstration. In addition, the embodied activity may involve inherent sections and units, such as conventional beat counts in a dance. The latter, however, need not be relevant in terms of interactional unit construction, as these boundaries may be rendered invisible under the constraints of action formation, such as instruction in many of the above excerpts.

Some bodily displays are timed for turn construction, while others are not. It will be a task for further research to outline all the relevant coordination types between the language and the body. One of the primary concerns in this regard may be reconsidering the analysis of preposed gestures: gestures are widely known to precede their lexical affiliates in talk (Schegloff, 1984; McNeill, 2005: 34-38) and the current study suggests that some of them might, in fact, complete the unit in progress. There is obviously a continuum of possibilities concerning the coordination of the body and units in talk, ranging from cases when verbal completion after embodied demonstration is absolutely relevant, to cases when it is optional, such as in dance instruction. These choices are partly enforced by activity-type and social norms. It is clear that in informal situations and adolescent talk there are lower demands on the primacy of verbal expression. Considering multimodal turn-construction across a variety of contexts as well as the role of different kinds of embodied displays (beyond bodily-vocal ones) in building turns could be interesting subjects for further study.

In the dynamic attempts to make sense in evolving real-time interaction, turn-constructional units are clearly epiphenomenal, but participants orient to them insofar as units capture the central facets of communicative action: initiation, projection and completion. Units furthermore cross-cut modalities: some grammatically projecting segments of talk can be considered as completed by a bodily demonstration, and then re-completed by language. Embodied displays may thus figure as turn-elements along the line with verbal segments. At the same time, they are not necessarily organized as regular turn-constructional units because of their different temporality. They may be initiated and continued during verbal segments but seem to be granted a special status when occupying a separate spate of time in a turn. In this way sequence structural vocal resources work together with bodily-visual ones to achieve meaningful action.

\section{Transcription conventions}

$\begin{array}{ll}\text { CAPS } & - \text { emphasis } \\ - & - \text { truncation of a word } \\ {[\text { ] }} & - \text { overlaps, simultaneous bodily displays } \\ = & - \text { latching turns } \\ (0.5) & - \text { pause length in tenths of a second } \\ (.) & - \text { micropause } \\ (\mathrm{x}) & - \text { unhearable syllable }\end{array}$




$\begin{array}{ll}\text { (insecure) } & - \text { insecure transcription } \\ : & - \text { lengthening of a sound } \\ ((\text { clap })) & - \text { transcriber's comments } \\ { }^{\circ} \text { silent } & \\ \uparrow & - \text { low volume } \\ . & - \text { distinct pitch movement upwards } \\ ? & - \text { pitch fall at the end of an intonation unit } \\ \text { - } & - \text { pitch rise at the end of an intonation unit } \\ \text { [space] }- & - \text { level pitch at the end of an intonation unit } \\ \text { /---/ } & - \text { unfinished intonation unit } \\ \end{array}$

\section{Abbreviations}

$\begin{array}{ll}\text { ALL } & \text { - allative } \\ \text { DEF } & - \text { definite } \\ \text { ELT } & \text { - elative } \\ \text { FUT } & \text { - future } \\ \text { PAR } & - \text { untranslatable particle } \\ \text { QUOT } & - \text { quotative } \\ \text { 3SG } & - \text { 3rd person singular }\end{array}$

\section{References}

Auer, Peter, 1992. The neverending sentence: rightward expansion in spoken language. In: Kontra, M., Váradi, T. (Eds.), Studies in spoken languages: English, German, Finno-Ugric. Linguistics Institute, Hungarian Academy of Sciences, Budapest, pp. 41-59.

Auer, Peter, 2005. Projection in interaction and projection in grammar. Text 25 (1), 7-36. Auer, Peter, 2009. Projection and Minimalistic Syntax in Interaction. Discourse Processes 46 (2), 180-205.

Broth, Mathias, Keevallik, Leelo (in press). Getting ready to move as a couple. Accomplishing mobile formations in a dance class. Space and Culture.

Couper-Kuhlen, Elizabeth, Ono, Tsuyoshi (Eds.), 2007a. Special issue: Turn continuation in cross-linguistic perspective. Pragmatics 17 (4).

Couper-Kuhlen, Elizabeth, Ono, Tsuyoshi, 2007b. 'Incrementing' in conversation. A comparison of practices in English, German and Japanese. Pragmatics 17 (4), $513-552$.

Enfield, Nick, 2009. The Anatomy of Meaning: Speech, Gesture, and Composite Utterances. Cambridge University Press, Cambridge.

Eriksson, Mats, 1995. A case of grammaticalization in Modern Swedish: The use of $b a$ in adolescent speech. Language Sciences 17 (1), 19-48.

Ford, Cecilia, 2004. Contingency and units in interaction. Discourse Studies 6 (1), 27-52.

Ford, Cecilia E., Fox, Barbara A., Thompson, Sandra A., 1996. Practices in the construction of turns: the "TCU" revisited. Pragmatics 6 (3), 427-454.

Ford, Cecilia E., Thompson, Sandra A., 1996. Interactional units in conversation: syntactic, intonational, and pragmatic resources for the management of turns. In: Ochs, E. Schegloff, E.A., Thompson, S.A. (Eds.), Interaction and Grammar. Cambridge: Cambridge University Press, Cambridge, pp. 134-184.

Ford, Cecilia E., Thompson, Sandra A., Drake, Veronika, 2012. Bodily-visual practices and turn continuation. Discourse Processes 49 (3-4), 192-212. 
Ford, Cecilia, Fox, Barbara, Thompson, Sandra A., 2002. Constituency and the grammar of turn increments. In: Ford, C., Fox, B., Thompson, S. (Eds.), The Language of Turn and Sequence. Oxford University Press, Oxford, pp. 14-38.

Fox, Barbara A., Robles, Jessica, 2010. It's like mmm: Enactments with it's like. Discourse Studies 12 (6), 715-738.

Golato, Andrea, 2000. An innovative German quotative for reporting on embodied actions: Und ich so/und er so 'and I'm like/and he's like'. Journal of Pragmatics 32 (1), 24-59.

Goodwin, Charles, 1980. Restarts, pauses, and the achievement of mutual gaze at turnbeginnings. Sociological Inquiry 50 (3-4), 272-302.

Goodwin, Charles, Goodwin, Marjorie Harness, 1987. Concurrent operations on talk: Notes on the interactive organization of assessments. IPrA Papers in Pragmatics 1 (1), $1-55$.

Goodwin, Charles, 2002. Time in action. Current Anthropology 43 (S4), 18-35.

Goodwin, Charles, Goodwin, Marjorie, Olsher, David, 2002. Producing sense with nonsense syllables: Turn and sequence in conversations with a man with severe aphasia. In: Ford, C., Fox, B., Thompson, S. (Eds.), The Language of Turn and Sequence. Oxford University Press, Oxford, pp. 56-80.

Gullberg, Marianne, 1998. Gesture as a Communication Strategy in Second Language Discourse: A Study of Learners of French and Swedish. Lund University Press, Lund.

Hayashi, Makoto, 2005. Joint turn construction through language and the body: Notes on embodiment in coordinated participation in situated activities. Semiotica 156 (1/4), 21-53.

Haviland, John B., 2007. Master speakers, master gestures: a string quartet master class. In: Duncan, S.D., Levy, E.T., Cassell, J. (Eds.), Gesture and the Dynamic Dimension of Language: Essays in honor of David McNeill. John Benjamins, Amsterdam/Philadelphia, pp. 147-172.

Iwasaki, Shimako, 2011. The multimodal mechanics of collaborative unit construction in Japanese conversation. In: Streeck, J., Goodwin, C., LeBaron, C. (Eds.), Embodied Interaction: Language and Body in the Material World. Cambridge University Press, Cambridge UK, pp. 106-120.

Keevallik, Leelo, 2003. From Interaction to Grammar: Estonian Finite Verb Forms in Conversation. Acta Universitatis Upsaliensis: Studia Uralica Upsaliensia 34. Uppsala University, Uppsala.

Keevallik, Leelo, 2010. Bodily Quoting in Dance Correction, Research on Language and Social Interaction 43 (4), 401-426.

Keevallik, Leelo, 2013. The Interdependence of Bodily Demonstrations and Clausal Syntax, Research on Language and Social Interaction 46 (1), 1-21.

Li, Xiaoting, 2013. In: Szczepek Reed, B., Raymond, G. (Eds.), Units of Talk: Units of Action. John Benjamins, Amsterdam/Philadelphia, pp. 343-376.

Linell, Per, 2013. The dynamics of incrementation in utterance-building: Processes and resources. In: Szczepek Reed, B., Raymond, G. (Eds.), Units of Talk: Units of Action. John Benjamins, Amsterdam/Philadelphia, pp. 57-90.

Martin, Cathrin, 2004. From Other to Self. Learning as Interactional Change. Acta Universitatis Upsaliensis: Uppsala Studies in Education 107. Uppsala University, Uppsala.

McNeill, David, 2005. Gesture and Thought. University of Chicago Press, Chicago, London. Mondada, Lorenza, 2006. Participants' online analysis and multimodal practices: projecting the end of the turn and the closing of the sequence. Discourse Studies 8 (1), 
$117-129$.

Mondada, Lorenza, 2007. Multimodal resources for turn-taking: Pointing and the emergence of possible next speakers. Discourse Studies 9 (2), 195-226.

Mori, Junko, Hayashi, Makoto, 2006. The achievement of intersubjectivity through embodied completions: A study of interactions between first and second language speakers. Applied Linguistics 27 (2), 195-219.

Murphy, Keith M., 2005. Collaborative imagining: The interactive use of gestures, talk, and graphic representation in architectural practice. Semiotica $156(1 / 4), 113-145$.

Olsher, David, 2004. Talk and gesture: The embodied completion of sequential actions in spoken interaction. In: Gardner, R., Wagner, J. (Eds.), Second Language Conversations. Continuum, London, pp. 221-245.

Ono, Tsuyoshi, Couper-Kuhlen, Elizabeth, 2007. Increments in cross-linguistic perspective: Introductory remarks. Pragmatics 17 (4), 505-512.

Sacks, Harvey, Schegloff, Emanuel A., 2002. Home position. Gesture 2 (2), 133-146.

Sacks, Harvey, Schegloff, Emanuel A., Jefferson, Gail, 1974. A simplest systematics for the organization of turn-taking for conversation. Language 50 (4), 696-735.

SAOL - Svenska Akademiens Ordlista. [The Comprehensive Dictionary of Swedish.] http://www.svenskaakademien.se/svenska_spraket/svenska_akademiens_ordlist a/saol_pa_natet/ordlista

Schegloff, Emanuel A., 1984. On some gestures' relation to talk. In: Atkinson, J.M. and Heritage, E. J. (Eds.), Structures of Social Action: Studies in Conversation Analysis. Cambridge University Press, Cambridge, pp. 266-296.

Schegloff, Emanuel A., 1996. Turn organization: one intersection of grammar and interaction. In: Ochs, E. Schegloff, E.A., Thompson, S.A. (Eds.), Interaction and Grammar. Cambridge: Cambridge University Press, Cambridge, pp. 52-133.

Selting, Margret, 2000. The construction of units in conversational talk. Language in Society 29 (4), 477-517.

Seo, Mi-Suk, Koshik, Irene, 2010. A conversation analytic study of gestures that engender repair in ESL conversational tutoring. Journal of Pragmatics 42 (8), 2219-2239.

Sidnell, Jack, 2006. Coordinating gesture, talk, and gaze in reenactments. Research on Language and Social Interaction 39 (4), 377-409.

Stivers, Tanya, Sidnell, Jack, 2005. Multi-modal interaction. Semiotica 156 (1/4), 1-20.

Streeck, Jürgen, 2002. Grammars, words, and embodied meanings: On the uses and evolution of so and like. Journal of Communication 52 (3), 581-596.

Tolins, Jackson, 2013. Assessment and Direction Through Nonlexical Vocalizations in Music Instruction, Research on Language and Social Interaction 46 (1), 47-64.

Weeks, Peter, 1996. A rehearsal of a Beethoven passage: An analysis of correction talk. Research on Language and Social Interaction 29 (3), 247-290. 